\title{
Establishment risk of the commercially imported bumblebee Bombus terrestris dalmatinus - can they survive UK winters?
}

\author{
Emily L. Owen, Jeffrey S. Bale, Scott A. L. Hayward \\ School of Biosciences, University of Birmingham, Edgbaston, Birmingham B15 2TT, UK \\ Received 13 April 2015 - Revised 2 June 2015 - Accepted 25 June 2015
}

\begin{abstract}
Bumblebees are regularly exported to countries outside their native range for the purposes of commercial pollination. In contrast to the tight regulations imposed on biological control introductions, the movement of bumblebees has largely been without risk assessment. This study represents the first formal assessment of establishment risk for Bombus terrestris dalmatinus in the UK. The ability of workers to survive winter conditions is seen as the primary barrier to establishment, given the year-round colony activity of this sub-species. We use standardised cold tolerance indices as outlined by the EU policy support action 'REBECA' as well as assessing rapid cold hardening ( $\mathrm{RCH})$ ability. Cold tolerance was comparable to that of the UK-native Bombus terrestris audax, including a strong RCH response. Results suggest that $B$. $t$. dalmatinus could survive mild UK winters in southern areas and potentially displace $B$. t. audax. The implications of ongoing climate change on establishment risks are discussed.
\end{abstract}

\section{bumblebee / cold tolerance / rapid cold hardening / native / winter}

\section{INTRODUCTION}

Given the economic importance of insect pollination (Gallai et al. 2009) and the decline of the north American honeybee, Apis mellifera, (Tentcheva et al. 2004), alternative pollinators have increasingly been used to enhance the yield and quality of commercially valuable crops. In the past 50 years, demand for commercial pollination has increased by $300 \%$, yet there has only been a $45 \%$ increase in managed honey bee hives (Aizen et al. 2008). Due to improvements in mass rearing methods, bumblebees have been employed as commercial pollinators since 1988 (Inari et al. 2005) and are now the sole

Corresponding author: S. Hayward,

s.a.hayward@bham.ac.uk

Manuscript editor: James Nieh pollinators of certain crops such as tomatoes. In 2004, 40,000 ha of greenhouse tomatoes (Lycopersicon esculentum) worldwide were pollinated by bumblebees, with an estimated value of $€ 12,000$ million (Velthuis and van Doorn 2006). Bumblebees are also deployed in the pollination of alfalfa (Medicago sativa), clover (Trifolium spp.), oilseed rape (Brassica napus), brown mustard (Brassica juncea), sunflower (Helianthus annuus) and fruits such as strawberry (Fragaria $\times$ ananassa), melon (Cucumis melo) and kiwifruit (Actinidia deliciosa) (Goulson 2010). Key to their success is the ability to 'buzz pollinate' (Buchmann 1983) by moving their flight muscles rapidly, causing the flower and anthers to vibrate which dislodges pollen and enhances the efficiency of pollen harvesting 400-fold (Winter et al. 2006).

The most widely used bumblebee in a commercial setting is Bombus terrestris dalmatinus (Ings et al. 2005a), due to the large size of workers and 
high success rate of colonies, e.g. easy commercial production of large colony numbers, and benefits for farmers including lower production costs, increased yields and improved fruit quality (Velthuis and van Doorn 2006). This subspecies is native to South East France, Northern Italy, the Balkanic Peninsulas, Turkey and North Iran, (Rasmont et al. 2008). However, approximately one million colonies were transported across 57 countries in 2006, 16 of which are outside its native range (Ings 2006). Because precautions were not undertaken to assess establishment risk (Velthuis and van Doorn 2006), establishment occurred in Japan, Chile, Argentina, Israel, New Zealand and Tasmania (McFadyen and Lloyd 2006; Goka 2010). There was also concern regarding potential competitive displacement of native bee species, heightened in areas of sparse floral resources (Ings et al. 2005b; Goulson 2003). Studies of exotic invaders competing with native species abound within the literature (Radville et al. 2014) and can occur rapidly where there is considerable overlap in habitat and other resource requirements (Short and Petren 2012) — which is often true of competing Bombus spp. (Dohzono and Yokoyama 2010). There are many well-documented examples for bees, including introduced $A$. mellifera outcompeting native solitary and honey bees on Tenerife (Dupont et al. 2004). While in Tasmania, foraging by native solitary bees is prevented by the presence of non-native $B$. terrestris (Hingston and McQuillan 1999). Competition for nest sites between native bees and $B$. terrestris can further decrease species richness and abundance (Hingston and McQuillan 1999; Goulson 2003).

Commercial colonies of B.t. dalmatinus are regularly imported into the UK, despite having a native population of Bombus terrestris audax. Control measures to prevent establishment have only been recently introduced, with 'queen excluders' (devices which prevent queens from exiting colonies) mandatory since January 2013 (Natural England 2013). However, given the scale of importation to the UK (10,000 colonies annually), it is possible that some $B . t$. dalmatinus queens may have escaped. To date, no formal assessment of establishment risk has been undertaken in the UK, although there is emerging evidence that $B$. $t$. dalmatinus may have become established in the southern UK (Ings et al. 2006). This is of concern because Ings et al. (2006) found consistently higher nectar foraging rates and an increased production of gynes in B.t. dalmatinus, suggesting that it could outcompete the native B.t. audax .

The life cycle of $B$. terrestris in Northern Europe has been extensively researched and is well understood (Goulson 2010). In early spring, mated overwintered queens emerge from diapause (Rasmont et al. 2008), establish a nest and feed their first brood of larvae with pollen to initiate colony development (Beekman and van Stratum 2000). Emerging workers then tend to all further eggs (Sladen 1912). Egg laying continues until late summer when new diploid queens and haploid males are produced (Gadau et al. 2001). New queens then accumulate glycogen reserves, mate, locate suitable hibernacula and enter the 'diapause' state (Alford 1969). Males and remaining workers within the colony die at the onset of winter. This is in contrast to $B$. $t$. dalmatinus which, in their native Mediterranean environment, typically remain active throughout the year, except for a period of summer aestivation - although a winter diapause has been documented in alpine regions of Turkey (Gurel et al. 2008). An important barrier to the establishment of non-native species in regions with a seasonal climate is winter cold (Bale and Hayward 2010). Thus, the phenology of $B$. t. dalmatinus may be maladapted to the UK climate by producing winter-active colonies instead of queens entering diapause. Interestingly, climate warming appears to have driven $B . t$. audax towards producing winter-active colonies in the southern UK (Stelzer et al. 2010), and active workers could potentially survive mild UK winter conditions (Owen et al. 2013). This has never been assessed for B. $t$ dalmatinus but is key to determining whether this sub-species could become established and possibly displace the native B. $t$. audax? The life expectancy of winter colonies would then depend on temperatures not dropping below the tolerance limits of workers and queens as well as access to forage. With good evidence that several important pollen sources persist throughout UK winters in urban environments (Ings et al. 2006), understanding the 
physiological limits of winter survival is extremely important.

There exists an extensive literature on insect cold tolerance and its application in assessing the establishment risk of introduced species (Hatherly et al. 2005; Hughes and Bale 2009; Hughes et al. 2010; Coombs and Bale 2014). Indeed, these assessments form the basis of commercial licensing to release biocontrol agents in several EU countries (REBECA 2014). Ecologically relevant indices of cold tolerance are used to inform the likelihood of establishment of an insect, including the use of lethal time (LTime) and lethal temperature (LTemp) experiments(Owen et al. 2013), which assess survival after exposure to acute and chronic low temperatures. In the current study, we use the same indices to determine the likelihood of establishment of the non-native bumblebee $B . t$. dalmatinus in the UK. In addition, we assess the capacity of winter-active workers to respond rapidly to environmental variability through a process of rapid cold hardening $(\mathrm{RCH})$, which is also important for winter survival (Lee et al. 1987). We directly compare the cold tolerance of $B . t$. dalmatinus with $B$. t. audax and determine the likelihood of establishment of $B$. t. dalmatinus in the UK.

\section{MATERIALS AND METHODS}

\subsection{Culture system}

Mature colonies of B.t. dalmatinus were obtained from Biobest NV (Westerlo, Belgium) and maintained at $20{ }^{\circ} \mathrm{C}$ in constant darkness. Bees were manipulated under red illumination to minimise disturbance (Sadd 2011). Nectar was available within the colony using a wick system connected to a reservoir of BioGluc ${ }^{\mathbb{B}}$ nectar, and pollen paste was available ad libitum (Biobest NV). In total, 19 colonies were used, delivered in batches of two to five at regular intervals in 2013 (22 April, 15 May, 26 July, 22 August and 22 October). Preliminary experiments were conducted to determine whether individuals from each colony within a batch demonstrated significant differences in cold tolerance phenotypes: none did. Subsequently, individuals were selected randomly across all colonies within a batch for use in each experimental treatment (including controls). For each experimental treatment, $n=30$ worker bees were used, unless otherwise stated. Control samples of 30 bees were exposed to $15{ }^{\circ} \mathrm{C}$ for the maximum experimental duration, and survival (determined as ability to move) was assessed after $72 \mathrm{~h}$.

\subsection{Lethal temperature}

Bumblebees were placed into six test tubes ( $n=5$ per tube) containing type $\mathrm{K}$ exposed wire thermocouples to record body temperature. Tubes were placed into an alcohol bath (Haake Phoenix 11 P2, Thermo Electron Corporation), programmed to cool from $20^{\circ} \mathrm{C}$, at a rate of $0.2{ }^{\circ} \mathrm{C} \mathrm{min}{ }^{-1}$, to a range of sub-zero temperatures between -5 and $-8{ }^{\circ} \mathrm{C}$. Bumblebees were held at each temperature for $15 \mathrm{~min}$ before the temperature was increased back to $20{ }^{\circ} \mathrm{C}$ at the same rate and survival assessed as described earlier.

\subsection{Lethal time}

Workers were added in groups of five to six conical flasks (25 mL Pyrex) and placed inside a Fryka ${ }^{(B)}$ (B30 Cold Box, Fryka, Germany) incubator set at $0{ }^{\circ} \mathrm{C}$ for a range of durations, between 2 and 11 days (without access to food). Before and after each exposure, bees were held at $10{ }^{\circ} \mathrm{C}$ for $1 \mathrm{~h}$ to prevent the possibility of cold and heat shock mortality, respectively. Bumblebees were removed from the incubator, added to a recovery box, and survival was assessed as previously described.

\subsection{Rapid cold hardening}

Determination of the discriminating treatment was undertaken at $-5{ }^{\circ} \mathrm{C}$, as this was the lowest sub-zero temperature which induced mortality, whilst having no incidence of freezing (supercooling points (SCPs) ranged from -5.1 to $-10.1^{\circ} \mathrm{C}$ ). Worker bees were taken from their rearing temperature $\left(20^{\circ} \mathrm{C}\right)$, added to test tubes with thermocouples as previously described and placed directly in an alcohol bath set at $-5^{\circ} \mathrm{C}$ for a range of durations $(2,4,6,8$ and $10 \mathrm{~h}$; six replicates of $N=5$ per treatment). Bees were then re-warmed to rearing temperature at a rate of $0.2{ }^{\circ} \mathrm{C} \mathrm{min}^{-1}$, and survival was assessed. The shortest time duration that resulted in between 10 and $20 \%$ survival was selected as the discriminating treatment (Lee et al. 1987).

To assess the $\mathrm{RCH}$ response, bees were added to test tubes as previously described and exposed to one of two $\mathrm{RCH}$ regimes prior to transfer to the discriminating 
treatment: $1 \mathrm{~h}$ at $0{ }^{\circ} \mathrm{C}$ or gradual cooling at $0.2{ }^{\circ} \mathrm{C} \mathrm{min}^{-1}$ to $-5{ }^{\circ} \mathrm{C}$ (six replicates of $N=5$ per treatment). Rewarming to $20{ }^{\circ} \mathrm{C}$ and survival assessment were as previously described after $72 \mathrm{~h}$. Evidence of RCH was determined by any increase in survival relative to direct transfer to the discriminating treatment.

\subsection{Impact of RCH on supercooling point}

After a period of $1 \mathrm{~h}$ at $0{ }^{\circ} \mathrm{C}$, the SCPs of 30 workers were measured, using established methods (see Hughes and Bale 2009). Briefly, bees were inserted individually into test tubes containing type $\mathrm{K}$ exposed wire thermocouples and placed in an alcohol bath programmed to cool from $20{ }^{\circ} \mathrm{C}$ to $-20^{\circ} \mathrm{C}$ at a rate of $0.2{ }^{\circ} \mathrm{C} \mathrm{min}^{-1}$, and freezing exotherms were detected via a computerised recording system.

\subsection{Statistical analysis}

All results were tested for normality using a Kolmogorov-Smirnov test. LTemp $10,50,90$ and LTime $_{10,50,90}$ experiments were analysed via Probit analysis (Finney 1971) in Minitab ${ }^{\circledR}$ to identify the temperature at which 10,50 or $90 \%$ mortality occurred. $\mathrm{RCH}$ experiments were non-normally distributed, and so, independent samples Kruskal-Wallis tests with pairwise comparisons were undertaken on SPSS ${ }^{\mathbb{B}}$. $\mathrm{RCH}$ and SCP results were compared via a one-way ANOVA on Minitab ${ }^{\mathbb{P}}$.

\section{RESULTS}

\subsection{Lethal temperature}

Most B. $t$. audax workers $(96.6 \pm 3.3 \%)$ survived $15 \mathrm{~min}$ at $-5{ }^{\circ} \mathrm{C}$, but this decreased to just $6.7 \pm 4.2 \%$ survival following $15 \mathrm{~min}$ at $-8{ }^{\circ} \mathrm{C}$ (Figure 1). Probit analysis determined that LTemp $_{10,50,90}$ temperatures were $-4.6 \pm 1.0,-6.1$ \pm 1.0 and $-7.3 \pm 3.7{ }^{\circ} \mathrm{C}$, respectively (regression $P<0.001$, Pearson's goodness-of-fit $\left.\chi^{2}=15.4572, d f=4 P=0.004\right)$. There was no mortality in the control sample.

\subsection{Lethal time}

Worker survival was $96.7 \pm 3.3 \%$ following 2 days at $0{ }^{\circ} \mathrm{C}$ but declined rapidly to $20 \pm 5.2$ after
7 days at $0{ }^{\circ} \mathrm{C}$ (Figure 2). After 11 days, survival was $0 \%$. Probit analysis determined LTime $_{10,50,90}$ to be $2.5 \pm 1.1,4.8 \pm 1.1$ and $9.2 \pm 1.1$ days, respectively (regression $P<0.001$, Pearson's goodnessof-fit $\chi^{2}=2.6, d f=4 P=0.62$ ). There was no mortality in the control sample.

\subsection{Rapid cold hardening}

Mean survival of workers at $-5^{\circ} \mathrm{C}$ decreased with increasing duration of cold exposure, from $96.7 \pm 3.3 \%$ after 2 -h exposure, to $6.7 \pm 4.2 \%$ after 10 -h exposure (Figure 3 ); $8 \mathrm{~h}$ at $-5^{\circ} \mathrm{C}$ was chosen as the discriminating treatment $(13.3 \pm 4.2 \%)$. An independent samples Kruskal-Wallis test $(H=20.7, d f=4)$ with pairwise comparisons indicated that survival at 2 and $10 \mathrm{~h}, 4$ and $10 \mathrm{~h}$ and 2 and $8 \mathrm{~h}$ was significantly different $(P<0.01$, $<0.05,<0.05$, respectively).

Both pre-treatments induced a strong $\mathrm{RCH}$ response with $100 \%$ survival in workers cooled at $0.2 \mathrm{~min}^{-1}$ or exposed to $1 \mathrm{~h}$ at $0{ }^{\circ} \mathrm{C}$ prior to being placed at $-5{ }^{\circ} \mathrm{C}$ for $8 \mathrm{~h}$. This was significantly higher than survival as a result of direct transfer to $-5{ }^{\circ} \mathrm{C}$ for $8 \mathrm{~h}(H=22.6, d f=3, P<0.01)$.

A period of $1 \mathrm{~h}$ at $0{ }^{\circ} \mathrm{C}$ was sufficient to significantly decrease $(P<0.01)$ the SCP of workers, compared to controls (Table I). This suggests that $\mathrm{RCH}$ has the capacity to lower the SCP of workers and provides a mechanism for reducing freezing risk after a $\mathrm{RCH}$ pre-treatment at $0{ }^{\circ} \mathrm{C}$.

\section{DISCUSSION}

Characterising the ability of non-native terrestrial invertebrates to survive winter is deemed critical to assessing establishment risk at temperate latitudes (Bale and Hayward 2010). There is a considerable body of work addressing this issue for glasshouse biocontrol agents (Hatherly et al. 2005; Hughes and Bale 2009; Hughes et al. 2010; Coombs and Bale 2014), but far less attention has been paid to commercial pollinators. Commercial colonies of $B$. $t$. dalmatinus were first imported to the UK in 1989 (Kwon 2008), with no restrictions on their use until 2013 (Ings et al. 2005a). This led to concerns regarding establishment risk (Ings et al. 2006), and since 2013, B. t. dalmatinus has only 


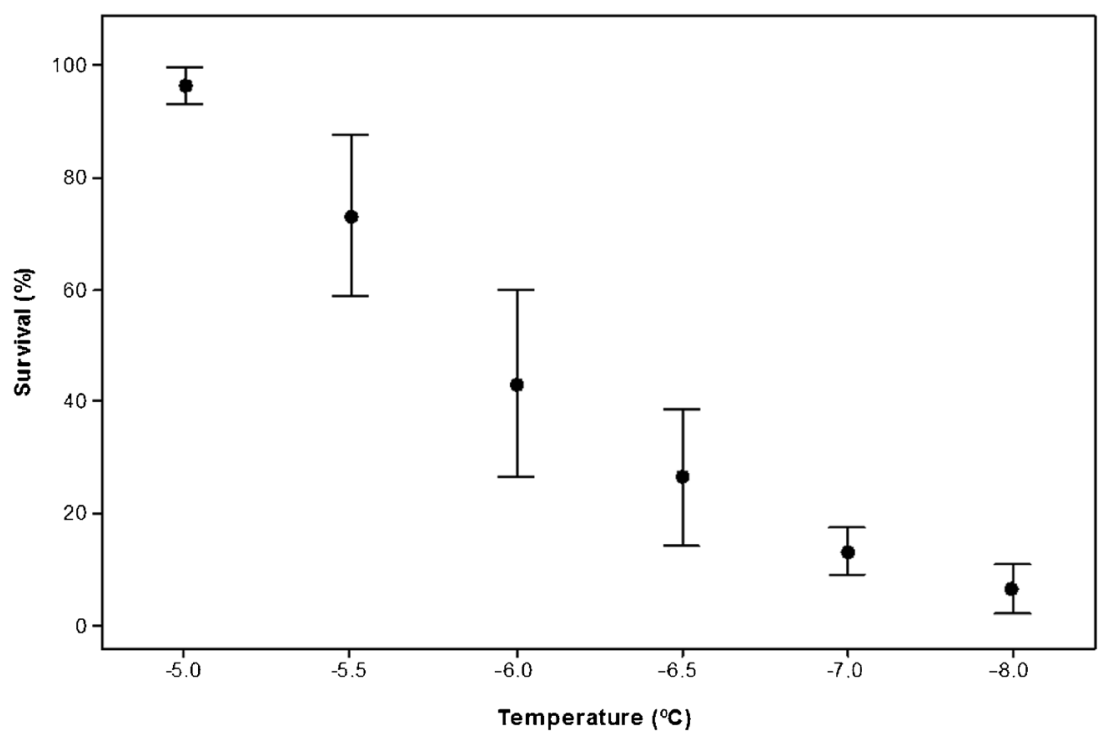

Figure 1. Survival of worker bumblebees (B. t. dalmatinus) held at a range of sub-zero temperatures for $15 \mathrm{~min}$. Each point represents six replicates of five bees \pm SEM.

been licensed for pollination in glasshouses and polytunnels in the UK, as well as colony boxes being fitted with queen excluders (Natural England 2013). However, clearly, some queens may have escaped prior to these restrictions coming into place. Given that this subspecies is typically active year round, it is pertinent to assess the ability of workers to survive UK winter conditions. This will formally assess establishment risk using the same criteria as other non-native insects and provide insight regarding whether $B$. $t$. dalmatinus might displace native $B$. t. audax .

This study has identified that $B$. t. dalmatinus is freeze avoiding (see Bale 1996), with limited

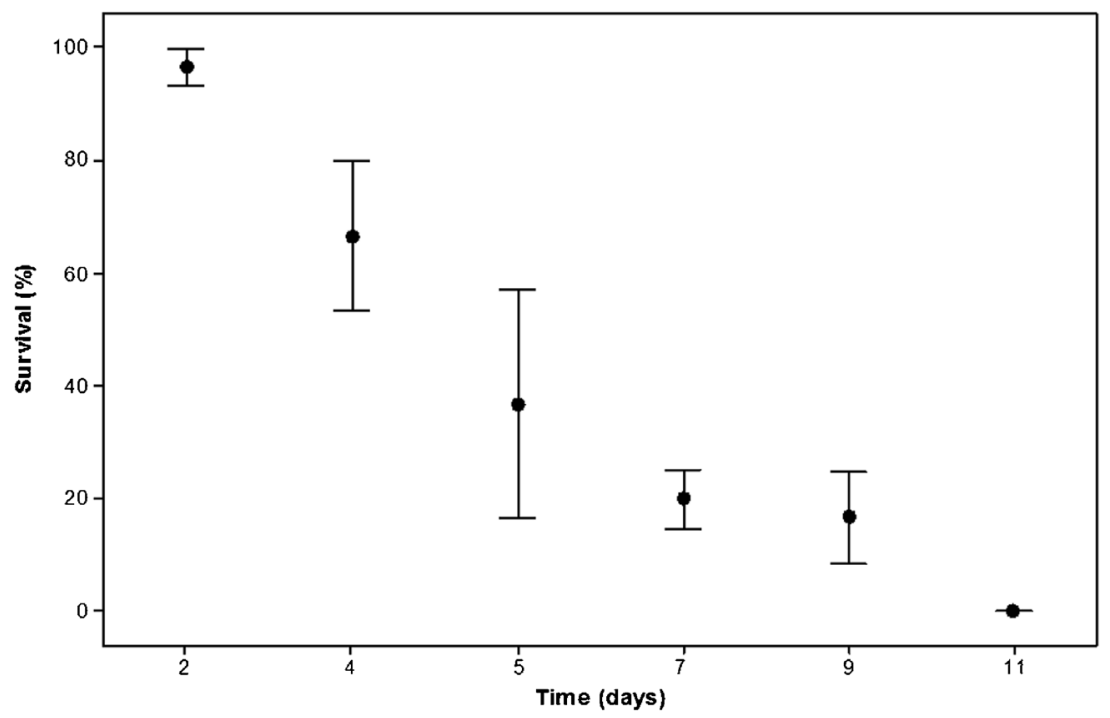

Figure 2. Survival of worker bumblebees (B. t. dalmatinus $)$ at a range of durations at $0{ }^{\circ} \mathrm{C}$. Each point represents six replicates of five bees \pm SEM. 


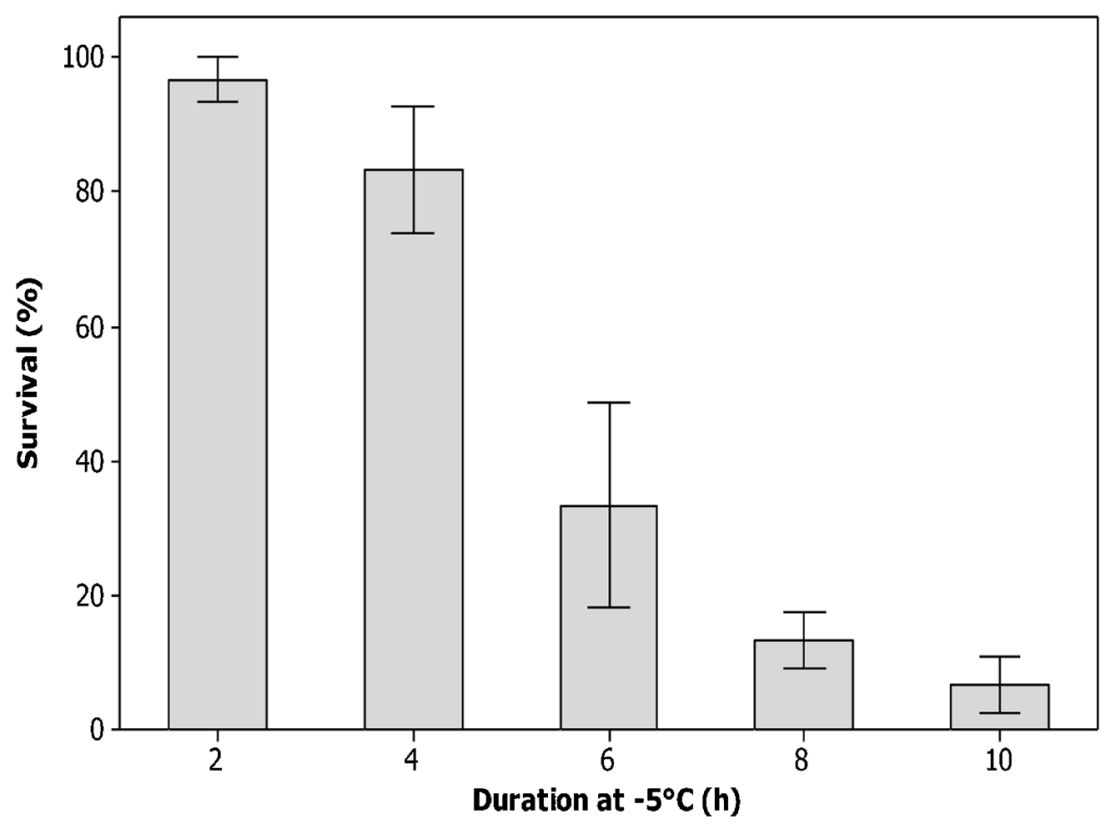

Figure 3. Determination of a discriminating treatment for rapid cold hardening in worker bumblebees (Bombus terrestris dalmatinus $)$. Mean survival $( \pm \mathrm{SEM})$ of worker bumblebees exposed to periods of $2,4,6,8$ and $10 \mathrm{~h}$ at $-5{ }^{\circ} \mathrm{C}, n=30$ per temperature.

supercooling ability (mean SCP of workers -7.1 \pm 0.2 ). This is comparable to the solitary bee Megachile rotundata $\left(-8^{\circ} \mathrm{C}\right.$; Sheffield 2008$)$ as well as B. $t$. audax $-7.1 \pm 0.2{ }^{\circ} \mathrm{C}$ (Owen et al. 2013). Despite this limited supercooling ability, workers were able to tolerate exposures to temperatures close to their SCP for short periods, e.g. $97 \pm 3.3 \%$ survived exposure to $-5{ }^{\circ} \mathrm{C}$ for $2 \mathrm{~h}$ (Figure 3). Survival declined dramatically at temperatures below $-5{ }^{\circ} \mathrm{C}$, however, with $50 \%$ mortality at $-6.1 \pm 1.0^{\circ} \mathrm{C}$, and it is likely that this was the result of freezing rather than cold shock. This level of cold tolerance is very similar to $B$. $t$. audax workers (Owen et al. 2013), suggesting a comparable ability to survive winter conditions outside the colony for short periods. To survive the entire winter, however, workers must forage to provision the colony. While there is good evidence that urban areas in parts of the UK provide sufficient floral resources over winter (Ings et al. 2006), foraging will expose workers to potentially rapid temperature fluctuations, for example, $0.03{ }^{\circ} \mathrm{C}$ min $^{-1}$ in Birmingham during winter 2011 (unpublished data). We identified a very strong RCH response in B. t. dalmatinus (Figure 4), which is again comparable to B.t. audax (Owen et al. 2013), and this could be important for winter survival. For example, if foraging workers were unable to return to the colony at night, they would be exposed more extreme sub-zero temperatures,

Table I. Impact of rapid cold hardening on supercooling point.

\begin{tabular}{llll}
\hline Treatment group & $\mathrm{N}$ & Mean $\pm \mathrm{SE}\left({ }^{\circ} \mathrm{C}\right)$ & Range $\left({ }^{\circ} \mathrm{C}\right)$ \\
\hline SCP control & 30 & $-7.1 \pm 0.2^{*}$ & -5.1 to -10.1 \\
SCP following RCH & 30 & $-8.4 \pm 0.2^{*}$ & -5.6 to -12.2 \\
\hline
\end{tabular}

The supercooling points of workers exposed to a pre-treatment of $1 \mathrm{~h}$ at $0{ }^{\circ} \mathrm{C}$ versus controls

*Significant $(F=12.4, d f=59 P<0.01)$ 


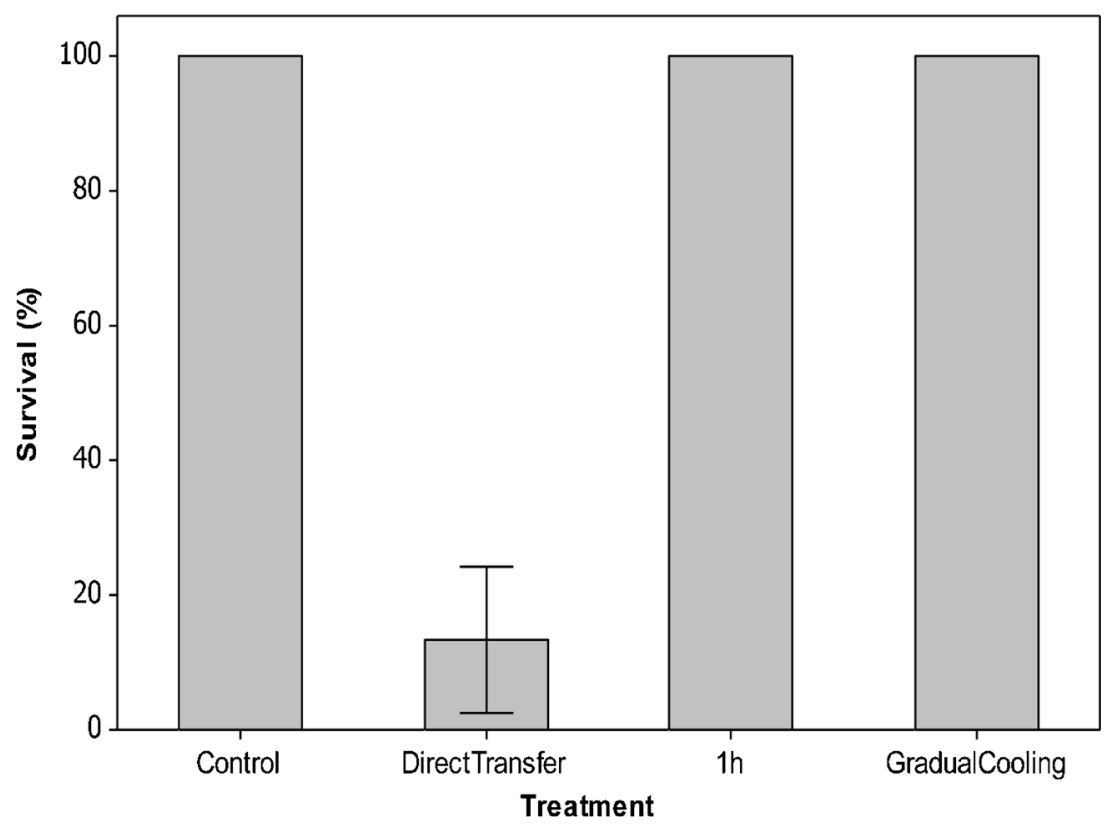

Figure 4. A rapid cold hardening response in worker bumblebees (Bombus terrestris dalmatinus). Mean survival $\left( \pm\right.$ SEM) of worker bumblebees after direct transfer to the discriminating treatment $\left(-5^{\circ} \mathrm{C}\right.$ for $\left.8 \mathrm{~h}\right)$, a pre-treatment of $1 \mathrm{~h}$ at $0{ }^{\circ} \mathrm{C}$ or gradual cooling (at $0.2 \mathrm{~min}^{-1}$ ) to the discriminating treatment. Each point represents six replicates of five bees \pm SEM.

e.g. $-7.7^{\circ} \mathrm{C}$ minimum temperature in Birmingham during February 2014 (Met Office 2014). Low temperatures of this nature have the potential to cause significant freezing mortality $\left(\right.$ LTemp $\left._{90}=-7.3^{\circ} \mathrm{C}\right)$; however, because RCH significantly lowered the SCP (Table I) and enhanced the cold tolerance of B. t. dalmatinus (Figure 4), the risk of freezing and/or pre-freeze mortality is reduced. Processes underpinning SCP reduction in other insects are thought to include the accumulation sodium chloride, urea, glycerol or glucose (Wilson et al. 2003), but this is yet to be studied in any bee species as B. t. dalmatinus and B. t. audax (Owen et al. 2013) are the only two Hymenoptera species for which $\mathrm{RCH}$ has been recorded to date. Lowering of the SCP during $\mathrm{RCH}$ is in contrast with several other insect species, for example, the Antarctic midge, Eretmoptera murphyi (Everatt et al. 2012), and house fly, Musca domestica (Coulson and Bale 1990). The capacity to RCH is not uncommon in Mediterranean species, however, and is thought to contribute to establishment potential (Nyamukondiwa et al. 2010).
Winter-active bees will, of course, not only be exposed to brief periods of sub-zero temperatures during foraging trips. They must also survive chronic cold within the colony. Subterranean temperatures often remain around $0{ }^{\circ} \mathrm{C}$ throughout winter (UK Environmental Change Network 2013), and while bumblebees possess the ability to thermoregulate their colonies to between 30 and $32{ }^{\circ} \mathrm{C}$ (Heinrich 1975), a lack of winter floral resources or an excessive thermoregulatory demand may mean that colonies are unable to consistently maintain a favourable temperature (Moret and Schmidt-Hempel 2000). This means that colony temperatures may equilibrate to the temperature of the surrounding earth for extended periods. B. t. dalmatinus workers experienced very little mortality following 2 days at $0{ }^{\circ} \mathrm{C}$ (Figure 2), but this increased to $50 \%$ after just $4.8 \pm 1.1$ days. These results are in line with LTime values for B. $t$. audax, with $50 \%$ mortality after 7.2 \pm 1.1 days (Owen et al. 2013). Whether this is a direct result of prolonged chilling or also a consequence of starvation needs to be further 
investigated, but metabolic rates were likely very low at $0{ }^{\circ} \mathrm{C}$ unless workers were actively trying to increase their body temperature during the treatment. Either way, winter-active colonies of both subspecies are likely to suffer significant mortality during typical northern European winters unless they are able to invest resources in maintaining colony temperature. However, this represents a significant thermoregulatory demand and would be predicted to negatively impact colony longevity, growth and subsequent production of new queens (Weidenmüller et al. 2002). Recent UK winters certainly appear to have been too cold for $B$. $t$. audax colonies to sustain colony development to the point of producing new queens, although worker numbers did persist for over 2 months of winter $(2012 / 13)$ in Birmingham, UK (Owen et al., unpublished data). Given the comparable cold tolerance of $B$. t. dalmatinus, a similar fate for winteractive colonies of this sub-species seems likely, indicating that a winter diapause strategy has a selective advantage under current conditions.

Climate change may further facilitate the establishment of $B$. $t$. dalmatinus, with estimated increases in global surface temperature of between 1 and $3.5^{\circ} \mathrm{C}$ by 2100 (Cannon 2004). Thus, in areas where both sub-species are winter active, the comparable cold tolerance of workers, combined with the larger size and superior foraging performance of B.t. dalmatinus (Ings et al. 2006), suggests that the non-native may outcompete B.t. audax. Competition is known to be heightened in areas of patchy floral resources (Goulson 2003), and phenological mismatching between plants and pollinators is predicted to exacerbate this problem (Schweiger et al. 2010). Under milder conditions, therefore, winter-active $B$. t. dalmatinus may be more effective at producing queens for the following spring. That said, a lack of diapause, even under favourable conditions, can have a negative impact on subsequent colony characteristics (Beekman and Van Stratum 2000), and this would require further investigation. There is also evidence that climate change might bring more frequent extreme cold events during winter (Rosenzweig et al. 2001), and under this scenario, it may be B. t. audax that has the advantage. This is because diapausing queens will be better able to survive than winter-active colonies. As outlined above, our own studies in the West Midlands indicate that neither sub-species could have survived recent winters as active colonies (Owen et al., unpublished data), so it is possible that a north-south divide may emerge defined by the 'decision' to enter diapause or not-with B. $t$. dalmatinus more successful in the south and B. t. audax at an advantage in the north. A similar driver of species distribution limits has been noted in the green stink bug, Nezara viridula, in Japan, where the timing of diapause induction determines the northern limit of winter survival (Musolin and Numata 2003). Given the unpredictability of year on year climate patterns, however, the key message from this study is the importance of conducting formal establishment risk assessments before releasing non-native insects, even if the subject is considered a beneficial pollinator.

\section{ACKNOWLEDGMENTS}

This work was funded by a $\mathrm{PhD}$ studentship awarded to Emily L. Owen by the Biotechnology and Biological Sciences Research Council (grant number BB/F016018/1). The authors gratefully acknowledge Dr. Thomas C. Ings (Anglia Ruskin University, UK) for his advice on working with B. t. audax and Biobest, Belgium, for the supply of bumblebees.

OPEN ACCESS This article is distributed under the terms of the Creative Commons Attribution 4.0 International License (http://creativecommons.org/licenses/by/4.0/), which permits unrestricted use, distribution, and reproduction in any medium, provided you give appropriate credit to the original author(s) and the source, provide a link to the Creative Commons license, and indicate if changes were made.

Risque d'installation du bourdon Bombus terrestris dalmatinus, importé commercialement: peut-il survivre aux hivers britanniques?

Bourdon / tolérance au froid / espèce indigène / adaptation au froid / Grande-Bretagne / espèce importée

Risikobewertung der Etablierung kommerziell importierter Hummeln, Bombus terrestris dalmatinus - können sie Winter in Grossbritannien überleben?

Hummel/ Kältetoleranz/ schnelle Kältestarre/ einheimisch/Winter 


\section{REFERENCES}

Aizen, M.A., Garibaldi, L.A., Cunningham, S.A., Klein, A.M. (2008) Long-term global trends in crop yield and production reveal no current pollination shortage but increasing pollinator dependency. Curr. Biol. 18, 1572-1575

Alford, D.V. (1969) A study of the hibernation of bumblebees (Hymenoptera: Bombidae) in Southern England. J. Anim. Ecol. 38, 149-170

Bale, J.S. (1996) Insect cold hardiness: a matter of life and death. Eur. J. Entomol. 93, 369-382

Bale, J.S., Hayward, S.A.L. (2010) Insect overwintering in a changing climate. J. Exp. Biol. 213, 980-994

Beekman, M., van Stratum, P. (2000) Does the diapause experience of bumblebee queens Bombus terrestris affect colony characteristics? Ecol. Entomol. 25, 1-6

Buchmann, S.L. (1983) Buzz pollination in Angiosperms. Handbook of Pollination Biology, Florence

Cannon, R.J.C. (2004) The implications of predicted climate change for insect pests in the UK, with emphasis on non-indigenous species. Glob. Chang. Biol. 4, 785-796

Coombs, M.R., Bale, J.S. (2014) Thermal biology of the spider mite predator Phytoseiulus macropilis . BioControl 59, 205-217

Coulson, S.J., Bale, J.S. (1990) Characterisation and limitations of the rapid cold-hardening response in the housefly Musca domestica (Diptera: Muscidae). J. Insect Physiol. 36, 207-211

Dohzono, I., Yokoyama, J. (2010) Impacts of alien bees on native plant-pollinator relationships: a review with special emphasis on plant reproduction. Appl. Entomol. Zool. 45, 37-47

Dupont, Y.L., Hansen, D.M., Valido, A., Olesen, J.M. (2004) Impact of introduced honey bees on native pollination interactions of the endemic Echium wildpretii (Boraginaceae) on Tenerife, Canary Islands. Biol. Conserv. 118, 301-311

Everatt, M.J., Worland, M.R., Bale, J.S., Convey, P., Hayward, S.A.L. (2012) Pre-adapted to the maritime Antarctic? Rapid cold-hardening of the midge, Eretmoptera murphyi. J. Insect Physiol. 58, 1104-1111

Finney, D.J. (1971) Probit Analysis. Cambridge University Press, Cambridge

Gadau, J., Gerloff, C.U., Kruger, N., Chan, H., SchmidHempel, P., Wille, A., Page, R. E. (2001) A linkage analysis of sex determination in Bombus terrestris (L.) (Hymenoptera: Apidae). Heredity $\mathbf{8 7}, 234-242$

Gallai, N., Salles, J.M., Settele, J., Vaissiere, B.E. (2009) Economic valuation of the vulnerability of world agriculture confronted with pollinator decline. Ecol. Econ. 68, 810-821

Goka, K. (2010) Introduction to the special feature for ecological risk assessment of introduced bumblebees: status of the European bumblebee Bombus terrestris in Japan as a beneficial pollinator and an invasive alien species. Appl. Entomol. Zool. 45, 1-6
Goulson, D. (2003) Effects of introduced bees on native ecosystems. Ann. Rev. Ecol. Evol. Syst. 34, 1-26

Goulson, D. (2010) Bumblebees: Behaviours, Ecology and Conservation. Oxford University Press, Oxford, UK

Gurel, F., Gosterit, A., Eren, Ö. (2008) Life-cycle and foraging patterns of native Bombus terrestris (L.) (Hymenoptera Apidae) in the Mediterranean Region. Insect. Soc. 55, 123-128

Hatherly, I.S., Hart, A.J., Tullett, A.G., Bale, J.S. (2005) Use of thermal data as a screen for the establishment potential of non-native biological control agents in the UK. BioControl 50, 687-698

Heinrich, B. (1975) Thermoregulation in Bumblebees. II Energetics of warm up and free flight. J. Comp. Physiol. 96, 155-166

Hingston, A.B..., McQuillan, P.B. (1999) Displacement of Tasmanian native megachilid bees by the recently introduced bumblebee Bombus terrestris (Linnaeus, 1758) (Hymenoptera: Apidae). Aust. J. Zool. 47, 59-65

Hughes, G.E., Bale, J.S. (2009) Thermal biology and establishment potential in temperate climates of the predatory mirid Nesidiocoris tenuis . BioControl 54, 785795

Hughes, G.E., Alford, L., Sterk, G., Bale, J.S. (2010) Thermal activity thresholds of the predatory mired Nesidiocoris tenuis: implications for its efficacy as a biological control agent. BioControl 55, 493-501

Inari, N., Nagamitsu, T., Kenta, T., Goka, K., Hiura, T. (2005) Spatial and temporal pattern of introduced Bombus terrestris abundance in Hokkaido, Japan, and its potential impact on native bumblebees. Popul. Ecol. 47, 77-82

Ings, T.C. (2006) Bombus terrestris, humble pollinator or assiduous invader? PhD Thesis, Queen Mary, University of London, UK

Ings, T.C., Raine, N.E., Chittka, L. (2005a) Mating preference in the commercially imported bumblebee species Bombus terrestris in Britain (Hymenoptera: Apidae). Entomol. Gen. 28, 233-238

Ings, T.C., Schikora, J., Chittka, L. (2005b) Bumblebees, humble pollinators or assiduous invaders? A population comparison of foraging performance in Bombus terrestris . Oecologia 144, 508-516

Ings, T.C., Ward, N.L., Chittka, L. (2006) Can commercially imported bumble bees out-compete their native conspecifics? J. Appl. Ecol. 43, 940-948

Kwon, Y. (2008) Bombiculture: a fascinating insect industry for crop pollination in Korea. Entomol. Res. 38, 66-70

Lee, R.E., Chen, C., Denlinger, D. (1987) A rapid cold hardening process in insects. Science 238, 1415-1417

McFadyen, R.E., Lloyd, S.G. (2006) Bumblebees: Implications of a new super-pollinator in mainland Australia. 15th Australian Weeds Conference, Papers and Proceedings: Managing Weeds in a Changing Climate. Adelaide, South Australia

Met Office (2014) Averages Table: Birmingham 19812010 [online] http://www.metoffice.gov.uk/public/ weather/climate/gcqdsfz6w (accessed on 26 July 14) 
Moret, Y., Schmidt-Hempel, P. (2000) Survival for immunity: the price of immune system activation for bumblebee workers. Science 290, 1166-1168

Musolin, D.L., Numata, H. (2003) Photoperiodic and temperature control of diapause induction and colour change in the southern green stink bug Nezara viridula. Physiol. Entomol. 28, 65-74

Natural England (2013) Licence to permit the release of non-native sub-species of the bumblebee (Bombus terrestris) in commercial glass-houses or polytunnels for crop pollination and research. Natural England, Class Licence WML-CL22

Nyamukondiwa, C., Kleyhans, E., Terblanche, J.S. (2010) Phenotypic plasticity of thermal tolerance contributes to the invasion potential of Mediterranean fruit flies (Ceratitis capitata). Ecol. Entomol. 35, 565-575

Owen, E., Bale, J.S., Hayward, S.A.L. (2013) Can winteractive bumblebees survive the cold? Assessing the cold tolerance of Bombus terrestris audax and the effects of pollen feeding. PLoS ONE 8, e80061

Radville, L., Gonda-King, L., Gomez, S., Kaplan, I., Preisser, E.L. (2014) Are exotic herbivores better competitors? A meta-analysis. Ecology 95, 30-36

Rasmont, P., Coppée, A., Michez, D., De Meulemeester, T. (2008) An overview of the Bombus terrestris (L. 1758) subspecies (Hymenoptera: Apidae). Ann. Soc. Entomol. Fr. 44, 243-250

REBECA (2014) Regulation of Biological Control Agents: General Practice [online] http://www.rebeca-net.de/ $? \mathrm{p}=370$ (accessed on 13 Nov 14)

Rosenzweig, C., Iglesius, A., Yang, X.B., Epstein, Y.B., Chivan, E. (2001) Climate change and extreme weather events - implications for food production, plant diseases, and pests. Glob. Chang. Hum. Health 2, 90-104

Sadd, B.M. (2011) Food-environment mediates the outcome of specific interactions between a bumblebee and its trypanosome parasite. Evolution 65, 2995-3001

Schweiger, O., Biesmeijer, J.C., Bommarco, R., Hickler, T., Hulme, P.E., et al. (2010) Multiple stressors on biotic interactions: how climate change and alien species interact to affect pollination. Biol. Rev. 85, 777-795
Sheffield, C.S. (2008) Summer Bees for Spring Crops? Potential Problems with Megachile rotundata (Fab.) (Hymenoptera: Megachilidae) as a Pollinator of Lowbush Blueberry (Ericaceae). J. Kansas Entomol. Soc. 81, 276-287

Short, K.H., Petren, K. (2012) Rapid species displacement during the invasions of Florida by the tropical house gecko Hemidactylus mabouia. Biol. Invasions 14, 1177-1186

Sladen, F. (1912) The Humble-Bee. Logaston Press, Little Logaston

Stelzer, R.J., Chittka, L., Carlton, M., Ings, T.C. (2010) Winter active bumblebees (Bombus terrestris) achieve high foraging rates in urban Britain. PLoS ONE 5, e9559

Tentcheva, D., Gauthier, L., Zappulla, N., Dainat, B., Cousserant, F., Colin, M.E., Bergoin, M. (2004) Prevalence and seasonal variations of six bee viruses in Apis Mellifera L. and Varroa destructor mite populations in France. Appl. Environ. Microbiol. 70, 71857191

UK Environmental Change Network: Rothamsted Research (2013) Temperature Data [online] http:// www.rothamsted.ac.uk/aen/ecn/ (accessed on 23 July 13)

Velthuis, H.H.W., van Doorn, A. (2006) A century of advances in bumblebee domestication and the economic and environmental aspects of its commercialization for pollination. Apidologie 37, 421-451

Weidenmüller, A., Kleineidam, C., Tautz, J. (2002) Collective control of nest climate parameters in bumblebee colonies. Anim. Behav. 63, 1065-1071

Wilson, P.W., Heneghan, A.F., Haymet, A.D.J. (2003) Ice nucleation in nature: Supercooling Point (SCP) measurements and the role of heterogeneous nucleation. Cryobiology 46, 88-98

Winter, K., Adams, L., Thorp, R., Inouye, D., Day, L., Ascher, J., Buchmann, S. (2006) Importation of Nonnative Bumble Bees into North America: Potential Consequences of Using Bombus terrestris and Other Non-native Bumble Bees for Greenhouse Crop Pollination in Canada, Mexico, and the United States. North American Pollinator Protection Campaign, San Francisco 